Correspondents are asked to be brief.

\begin{tabular}{|c|c|c|}
\hline 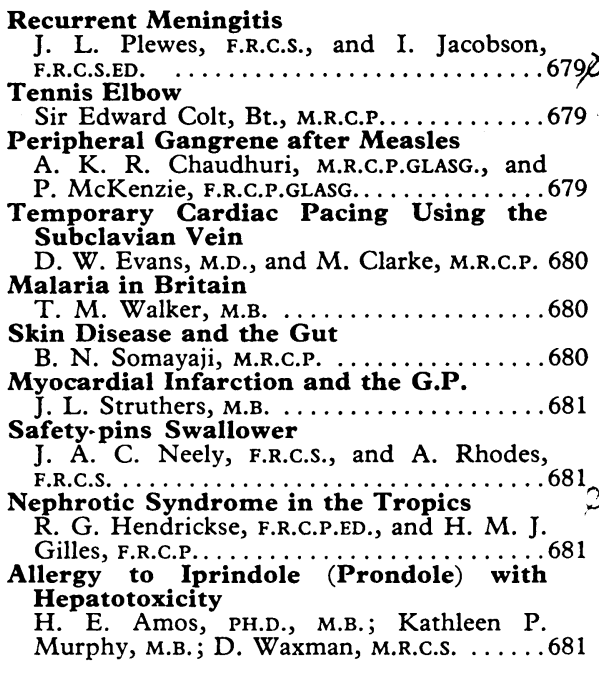 & 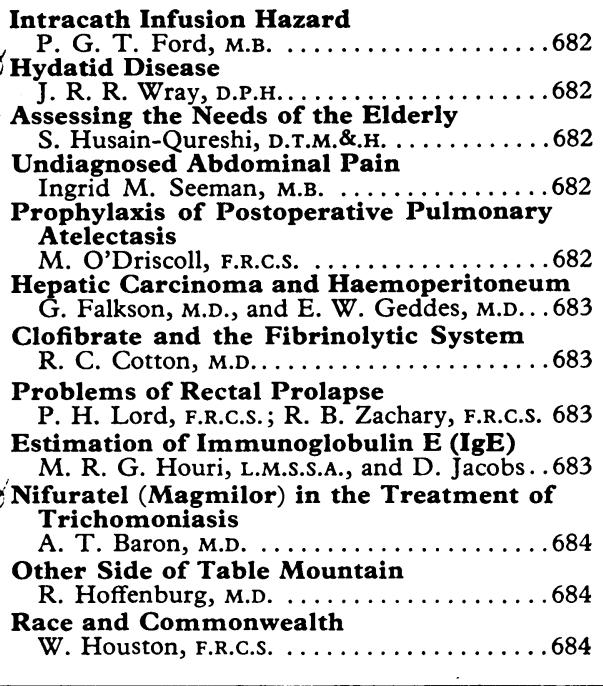 & $\begin{array}{l}\text { M. Sim, F.R.C.P.ED. } \\
\text { Endocrine Function in Hom } \\
\text { Christine G. Ryrie, PH.D., an } \\
\text { M.R.C.P. . . . . . . . . . } \\
\text { Living it up with Concorde } \\
\text { Major I. C. Perry, M.B. . . } \\
\text { Continuous Ventilation and } \\
\text { K. T. Tchen, F.F.A.R.C.S. }\end{array}$ \\
\hline
\end{tabular}

\section{Recurrent Meningitis}

SIR,-We have read with interest the medical memorandum on recurrent meningitis by Dr. O. G. Brooke and others (24 October, p. 218). From the accompanying $x$ ray films we would think that the incidental cystic findings at myelography are indeed sacral nerve root cysts, originally described in 1938 by Tarlov and then called perineurial cysts. ${ }^{1}$ Although the association in this case suggests a possible cause for the meningitis, we feel that the two are probably not related since the track of the sinus leads not to the cysts but rather to the most caudal part of the subarachnoid space.

Sacral nerve root cysts are an occasional myelographic finding and are most likely to be shown when the patient is rescreened after an interval. This necessity for delayed screening may be a factor accounting for the infrequent reports of sacral cysts. We believe that sometimes the cysts may be the tion. cause of sciatica in a patient who is diagnosed as having a disc protrusion and in whom it is subsequently not possible to confirm this either by myelography or at opera-

During the past three years we have encountered eight such patients, who have recently been reported elsewhere. ${ }^{2}$ In three of our patients the cysts were an incidental finding, while in the other five they were felt to be causing symptoms. Four of these latter patients were operated on in order to obliterate the cysts and relieve symptoms.We are, etc.,

J. L. Plewes. I. JACOBSON.

Royal Infirmary, Dundee.

\section{REFERENCES}

1 Tarlov, I. M., Archives of N'eurology and Psychiatry, 1938, 40, 1067.
2 Plewes, J. L., and Jacobson, I., Lancet, 1970, 2,
799.

\section{Tennis Elbow}

SIR,- Two years ago metal tennis racquets became widely available. From my own experience and that of others I believe that they have a marked tendency to cause tendonitis at vulnerable sites. Classical tennis elbow refers to tendonitis of the extensor aponeurosis at its insertion into the lateral epicondyle, but other common conditions are medial epicondylitis and bicipital tendonitis.

I had played tennis for 18 years without ever having had trouble with my arm, until I played regularly with a "Smasher"-a racquet made of aluminium alloy and manufactured by Spalding Company. During my first year of using this racquet I developed severe bicipital tendonitis which subsided only after total abstinence from the game during the winter months. After three months of play this year I developed medial epicondylitis which later extended to include both sides of the elbow. Then a friend told me that he had also had pain, first in the shoulder, and later in the elbow, a few months after he commenced using a "Smasher." But he said that his arm had returned to normal when he recommenced using a wooden racquet. The connexion struck me as fortuitous until the day I took out my wooden racquet for the first time in two years. I instantly noticed that the exquisite pain previously experienced at the moment of contact with the ball had gone. The impact had a diffuse quality which was in contrast to the sharp jerk from the metal one. From that moment I used a wooden racquet, and my elbow improved.

The advantage of the "Smasher" is that it is light and at the same time rigid so that the player can hit the ball very hard, but in return the ball hits his arm very hard. The shock wave passes unimpeded up the metal, whereas wood, with its natural suppleness, absorbs much of the impact. Presumably the sudden stretch, transmitted by the metal racquet, exceeds the elastic limit of the tendons.

I then spoke to the third man (not Orson
Welles) in this tale. Although he had played a lot of tennis and won many trophies while using wooden racquets, he had never had any trouble with his arm. However, after using a metal racquet regularly, he developed increasingly severe forearm pain which was maximal over the medial epicondyle. After returning to the use of a wooden racquet he experienced progressive relief.-I am, etc.,

EdWARD COLT.

Hyattsville,
Maryland, U.S.A.

\section{Peripheral Gangrene after Measles}

SIR,-We read with interest the case report of gangrene of digits after chickenpox by Drs. O. H. B. Gyde and D. L. Beales (31 October, p. 284). This prompts us to report a case of peripheral gangrene in a child following measles due to presumed intravascular coagulation.

A boy aged 2 years was admitted on 10 June 1969 with bronchopneumonia six days after the onset of measles. On admission he was acutely ill, pyrexial $\left(104^{\circ} \mathrm{F}\right.$; $40^{\circ} \mathrm{C}$.), dyspnoeic, and cyanosed. There was clinical and radiological evidence of bilateral bronchopneumonia. Repeated sputum culture and throat swab did not grow any pathogenic organisms. As he did not respond to ampicillin and cloxacillin, and his white count was only 2,300/cu.mm., with lymphocytes $54 \%$ and atypical mononuclear cells $5 \%$, the possibility of viral pneumonia was considered. The presence of a few groups of multinucleated giant cells in the sputum raised the possibility of giant cell pneumonia which is a rare complication of measles. Twenty-four hours after admission he became drowsy and comatose, and he had several bouts of generalized convulsive seizures. He had bilateral extensor plantar responses with a normal C.S.F. The clinical picture was compatible with measles encephalitis. The subsequent course was stormy, and to complicate matters further nine days after admission he developed several small 